\title{
Post-COVID-19 New Normal for Molecular Imaging Departments: A United Kingdom Perspective
}

\author{
Jessica Williams ${ }^{1}$, Emma Meadows ${ }^{1}$, and Manrita Singh $^{2}$ \\ ${ }^{1}$ Department of Molecular Imaging, HCA Healthcare UK, London, England; and ${ }^{2}$ Department of Molecular Imaging, University \\ College London Hospital, London, England
}

\begin{abstract}
Coronavirus disease 2019 has changed the way the world is navigated and has had a massive impact on health care. Depending on where you are in the world, the guidance on dealing with potential infected patients is varied. With the high risk of a second wave, it is important to learn from initial responses to plan for the future. With proper preparation, it is possible to minimize exposure and risk of contamination to individuals visiting molecular imaging departments. Such precautions will help departments operate at full capacity. From the widespread nature of this pandemic, a global perspective can be useful; what follows is the United Kingdom's perspective.
\end{abstract}

Key Words: molecular imaging; COVID-19; nuclear medicine; pandemic; U.K

J Nucl Med Technol 2020; 48:227-233

DOI: 10.2967/jnmt.120.252635

$\mathbf{T}$ he United Kingdom comprises England, Scotland, Wales, and Northern Ireland. According to United Nations data, the midyear-2020 population of the United Kingdom was estimated to be $68,886,000$. For reference, the United States had a midyear-2020 population of approximately $331,000,000$ (United Nations data). The United States is around 40 times larger in land mass than all of the United Kingdom.

The United Kingdom had approximately 304,500 cases and 42,600 deaths due to coronavirus disease 2019 (COVID19) as of June 20, $2020(1,2)$. The United Kingdom was one of the slowest in acting to implement restrictions, lockdowns, and social distancing rules. There has been some debate on whether the delay was because the government initially looked to create herd immunity and then backtracked $(3,4)$. Herd immunity is when a large portion of the population is resistant to a disease- either through vaccination or through recovery from previous infection-lowering the risk of those

Received Jun. 27, 2020; revision accepted Jul. 22, 2020.

For correspondence and reprints contact: Jessica Williams, HCA Healthcare UK, Harley Street Clinic, 154 Harley St., London, W1G 8BJ, U.K. E-mail: jess_williams@mac.com

Published online Jul. 24, 2020.

COPYRIGHT (c) 2020 by the Society of Nuclear Medicine and Molecular Imaging. who are vulnerable. Good examples of herd immunity are seen in polio and measles studies (5).

Once lockdown was implemented to help reduce infection rates on March 23, 2020, people in the United Kingdom were generally compliant. The advice directly from the government was to stay at home, visiting shops infrequently and only for essentials. Exercising outdoors once daily alone or with members of the same household was encouraged, as well as social distancing-keeping $2 \mathrm{~m}$ apart from members of other households. Only essential travel was permitted, with proof of necessity required. All shops that were nonessential, such as electronics, clothing, and department stores, shut for the duration of the lockdown. All gatherings were banned, and fines were implemented for those breaking any of these rules (6).

Nightingale, the name that was given to a series of COVID-19-specific field hospitals, was built. This construction was completed within a week in different areas of England to ease the burden of the National Health Service (NHS) (7). In England, the private sector opened its facilities to the NHS to alleviate the overwhelming need for hospital beds, ventilators, and clinical staff (8). Wearing face masks while on public transportation was made compulsory in England as of June 13, 2020, including on ride sharing services such as Uber, Bolt, and Kapten. Fines were imposed on those traveling without a face covering. In Scotland and Wales, face masks were advised, and in Northern Ireland they were encouraged in places where social distancing was not possible (9).

\section{ACUTE IMPACT ON PRACTICE}

When lockdown was initially imposed, greater consideration for imaging referrals was taken to include infection risk factors as well as radiation exposure, with particular reference to vulnerable groups. Vulnerable groups were identified as those over $70 \mathrm{y}$ of age and those with comorbidities such as lung, kidney, and heart disease. It was advised that nonurgent outpatient appointments be postponed until lockdown measures were relaxed. Only those patients whose course of treatment would be negatively impacted without imaging could keep their appointments. A traffic light system was devised and adopted by many facilities (Fig. 1) (10,11). 


\begin{tabular}{|c|c|c|}
\hline$\underline{\text { Red }}$ & Amber & Green \\
\hline $\begin{array}{l}\text { Do not cancel or rebook } \\
\text { unless patient at risk } \\
\text { Book all new referrals }\end{array}$ & $\begin{array}{l}\text { Discuss with clinician if there } \\
\text { is a need to cancel/rebook. } \\
\text { New referrals to be discussed }\end{array}$ & $\begin{array}{l}\text { Rebook without need for } \\
\text { discussion with a clinician }\end{array}$ \\
\hline${ }^{18} \mathrm{~F}-\mathrm{FDG}$ new cancer & ${ }^{18} \mathrm{~F}-\mathrm{FDG}$ follow up. & $\begin{array}{l}2 \text { phase bones and non-oncology } \\
\text { whole body bone }\end{array}$ \\
\hline${ }^{18} \mathrm{~F}-\mathrm{FDG}$ sepsis & ${ }^{88} \mathrm{Ga}$ DOTATATE follow up & Amyloid DPD \\
\hline $\begin{array}{l}\text { Ga or }{ }^{18} \mathrm{~F}-\mathrm{PSM} / \mathrm{N}^{18} \mathrm{~F}-\text {-Choline } \\
\text { new cancer }\end{array}$ & $\begin{array}{l}{ }^{68} \mathrm{Ga} \text { or }{ }^{18} \mathrm{~F}-\mathrm{PSM} / \mathrm{Al}^{18} \mathrm{~F}-\mathrm{Choline} \\
\text { follow up. }\end{array}$ & Benign ${ }^{131}$ thyroid therapy \\
\hline $\begin{array}{l}{ }^{68} \mathrm{Ga} \text { DOTATATE (staging / } \\
\text { therapy decision) }\end{array}$ & ${ }^{68} \mathrm{Ga}$ PSMA follow up & ${ }^{13} \mathrm{C}$ UBT \\
\hline GFR & Lung $\vee Q$ & Colonic transit \\
\hline Gl bleed & Mag3 . & CSF studies \\
\hline $\begin{array}{l}111 \text { In Pentetreotide } \\
\text { (Octreoscan) }\end{array}$ & MIBG pheochromocytoma & Dacroscintigraphy \\
\hline${ }^{177} \mathrm{Lu}$ DOTATATE & MPS routine (SOB) & DMSA \\
\hline Lung perfusion & MUGA - cardiac & Gastric emptying \\
\hline Meckels & $\begin{array}{l}\text { Parathyroid (bear in mind } \\
\text { cessation of drug therapy in lead } \\
\text { up) }\end{array}$ & HIDA \\
\hline MPS acute chest pain & Platelet & 123| loflupane (DaTSCAN) \\
\hline MUGA oncology & Thyroid $99 \mathrm{~m} T \mathrm{Tc}^{123}$ (paeds) & Lymphoscintigraphy \\
\hline Oncology bones & $\begin{array}{l}\text { White cell (also consider }{ }^{18} \mathrm{~F} \text { - } \\
\text { FDG) }\end{array}$ & MIBG heart \\
\hline${ }^{223} \mathrm{Ra}$ & & Morphine HIDA \\
\hline SLN & & Platelets \\
\hline $\begin{array}{l}\text { 99mTc-EDDA/HYNIC-TOC } \\
\text { (Tektrotyd) }\end{array}$ & & Proctoscintigraphy \\
\hline \multirow[t]{6}{*}{${ }^{90} \mathrm{Y}$-SIRT } & & Red cell mass \\
\hline & & Salivary \\
\hline & & $\begin{array}{l}75 \mathrm{Se} / \text { Tauroselcholic acid } \\
\text { (SeHCAT) }\end{array}$ \\
\hline & & Small bowel transit \\
\hline & & Thyroid ${ }^{99 \mathrm{~m}} \mathrm{Tc} /{ }^{123}$ (adults) \\
\hline & & ${ }^{201} \mathrm{TI}$ hibernation \\
\hline
\end{tabular}

FIGURE 1. Traffic light system guidance from the British Nuclear Medicine Society during COVID-19 pandemic. Green can be deferred, amber must be discussed with clinician before moving forward, and red is deemed essential and should not be cancelled or rescheduled (unless under extreme circumstances) (10).

the household has a high temperature or a new, continuous cough; whether the patient has a loss of or change in the normal sense of taste or smell; whether the patient or anyone in the household has had confirmed COVID-19 within the previous 14 days; whether the patient has been in contact with someone with confirmed COVID-19 within the previous 14 days; whether the patient has traveled outside the United Kingdom within the previous 14 days; and whether the patient has been told to self-isolate. Depending on how the patient answered, a contingency plan was suggested and followed (Fig. 2) (11). When possible, screens were placed at the reception desk to protect employees and patients. Patients were given a mask to be worn for the duration of their visit, and waiting areas were adapted to reduce capacity and allow for social distancing $(10,11)$.

New partnerships were founded between the NHS and private hospitals, allowing some departments to temporarily relocate specific services to private hospitals to reduce visits to high-risk NHS sites dealing with the COVID-19 outbreak. One example is sentinel node breast injection services, in which a breast is injected with a radioisotope to help localize the sentinel node before lymphectomy. Some sites that were authorized to perform breast surgery with radioactively labeled patients were given temporary permission to inject patients on-site, either in

Staffing recommendations were set up to minimize exposure to other staff and to patients. For example, some sites used extended shifts, which allowed for a 3- or 4-day working week to rotate staff, and many staff were encouraged to use up annual leave. Some facilities provided scrubs to be worn during a shift and then left onsite to be laundered by the facility, preventing staff from bringing home contaminated laundry. Personal protective equipment (PPE), including masks, gloves, aprons, and eye shielding, was provided for staff who would be within $2 \mathrm{~m}$ of a patient. Radiologists who previously reported studies onsite were set up to work from home to help minimize any exposure to staff and patients $(10,11)$.

Infection reduction techniques were put into effect immediately, including screening all staff and patients at building entrances by asking questions and enforcing handwashing with either soap or sanitizer on arrival. The questions to be asked were whether the patient or anyone in presurgical holding bays or in the operating room. This change was in lieu of the usual practice of injecting in the nuclear medicine department within NHS hospitals and then transferring the patients to private clinics for surgery. This new practice was facilitated by government legislation and accelerated approval pathways so as to not delay vital surgery or affect patient outcomes. A potential drawback to this scheme was no imaging capability at sites that did not have mobile $\gamma$-cameras; therefore, careful screening was paramount to ensure that imaging was not necessary (12).

Another area that was affected immediately was research. Most institutions suspended their projects at the onset of the pandemic (11). However, because of video conferencing technology such as Zoom, education and noncontact research has blossomed. Physicists and technologists have been working on radiation monitoring projects using patient records to establish new guidance and base levels that 


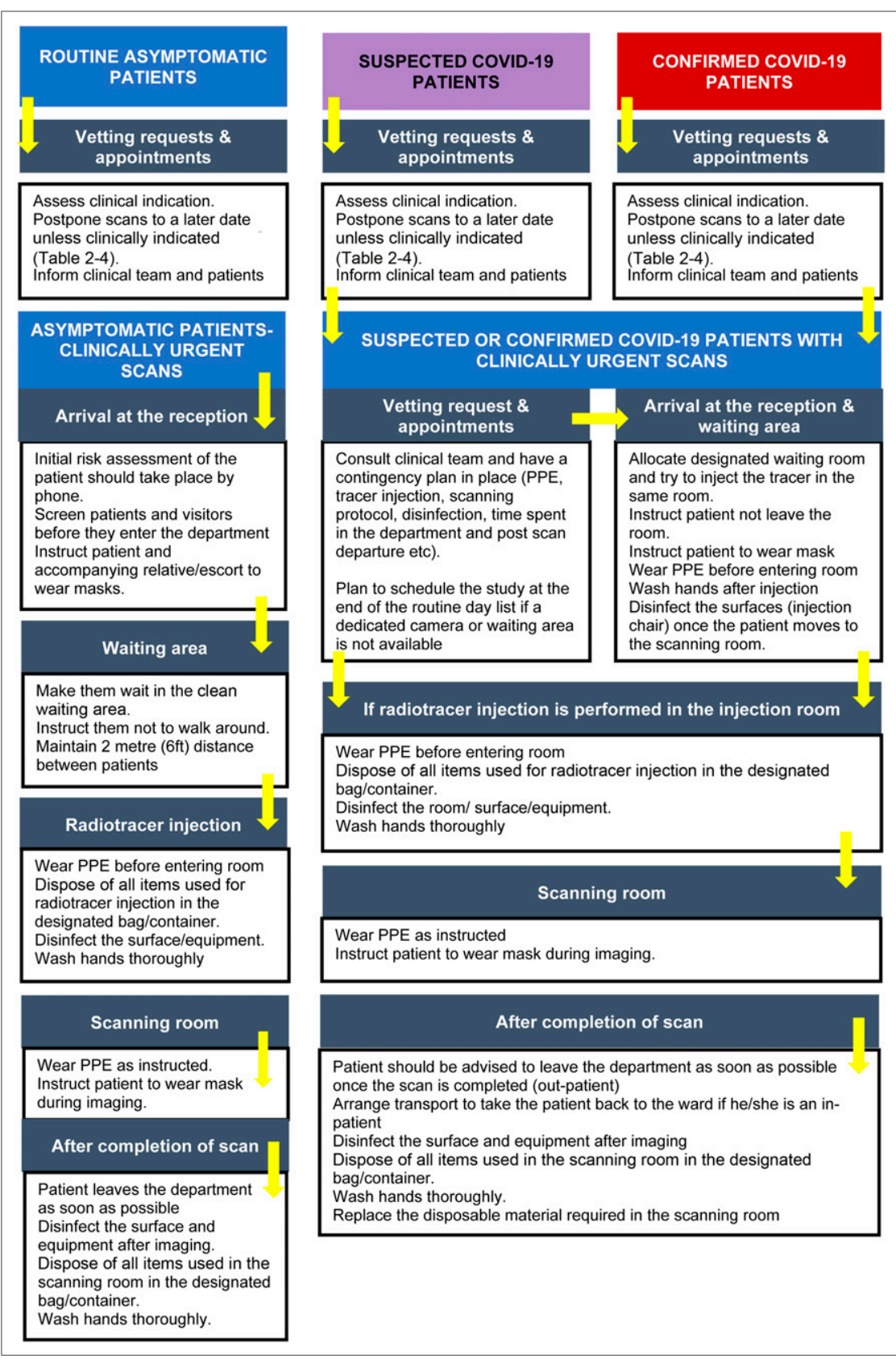

FIGURE 2. Contingency plan for molecular imaging departments $(11,20)$. practices to help avoid exposure to everyone until COVID-19 is eradicated. Measures implemented during the first wave are likely to become the norm. The British Society of Nuclear Medicine published COVID-19 recovery phase guidelines that, alongside the aforementioned practices, have guided departments back into recommencing nonurgent imaging and nonimaging procedures (15). A recently released video from HCA Healthcare UK, a private hospital system in the United Kingdom, highlights what patients can expect when attending one of their facilities $(16,17)$.

\section{Triage}

Patients on the waiting list from the time of the pandemic should be given priority for appointments. If the facility is following the traffic light system (Fig. 1), patients in the red should be prioritized, followed by amber and then green. On booking, it is best to ensure that patients do not have any active symptoms of COVID-19 and are not self-isolating (staying at home because of suspected exposure to COVID 19). Under these circumstances, it is best practice to reschedule appointments. Dependent on the facility, it may be best to advise patients not to bring guests with them unless medically necessary. If patients require an aerosol-based test (e.g., ventilation lung scan), a different level of PPE may be required. Public Health England published a PPE guidance chart (Figs. 3 and 4).

\section{Waiting Room}

There needs to be an area, at or near the entrance, in which everyone entering can clean their hands with either soap or sanitizer. On arrival, all persons have been neglected in the past. Education has continued remotely through online webinars such as U.K. Imaging and Oncology Online (13). This adaptation holds promise for the future, making training more accessible to the community with the bonus of reduced time off and reduced expenditures-issues that often prevent attendance by those in less supportive work environments (14).

\section{POST-COVID-19 PRACTICE}

Once the lockdown restrictions have been relaxed, molecular imaging departments need to examine business should be greeted and then instructed to clean their hands immediately. Everyone entering should have their temperature taken by a trained individual wearing appropriate PPE. These temperatures should be recorded, along with the answers to the screening questions. Patients and essential caregivers should be given a mask to wear for the duration of their visit. If possible, screens or clear acrylic shields should be placed at the reception desk to protect staff and patients. Clear signage should be visible for handwashing stations, temperature-checking stations, and any adaptations that have been made to the site for COVID-19. There should be lines of demarcation or stickers 


\begin{tabular}{|c|c|c|c|c|c|c|c|c|}
\hline \multicolumn{9}{|c|}{$\begin{array}{l}\text { Recommended PPE for healthcare workers by secondary care } \\
\text { inpatient clinical setting, NHS and independent sector }\end{array}$} \\
\hline Setting & Context & $\begin{array}{l}\text { Disposable } \\
\text { clives }\end{array}$ & $\begin{array}{l}\text { Disposabble } \\
\text { Plastic Apron }\end{array}$ & 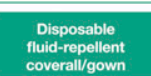 & $\begin{array}{l}\text { Surgical } \\
\text { mask }\end{array}$ & 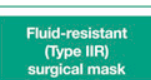 & $\begin{array}{c}\text { Filtering face } \\
\text { piece respirator }\end{array}$ & $\begin{array}{c}\text { Evefrace } \\
\text { protection' }\end{array}$ \\
\hline \multirow{9}{*}{ 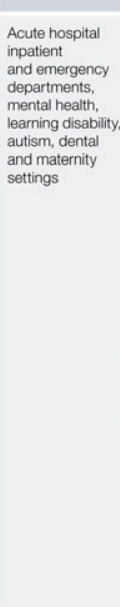 } & 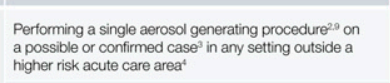 & $\checkmark$ single uses & $x$ & $\checkmark$ single uses & $x$ & $x$ & $\checkmark$ single uses & $\checkmark$ single uses \\
\hline & $\begin{array}{l}\text { Working in a higher isis acute care areat with possible or } \\
\text { confimed cases(s) }\end{array}$ & $\checkmark$ single uses & $\checkmark$ single uses & $\checkmark$ sessional usee & $x$ & $x$ & $\checkmark$ sessional usee & $\checkmark$ sessional uses \\
\hline & 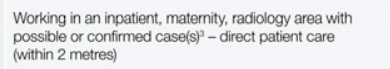 & $\checkmark$ single uses & $\checkmark$ single uses & $x$ & $x$ & $\checkmark$ sessional usee & $x$ & $\checkmark$ sessional uses \\
\hline & $\begin{array}{l}\text { Working in an inpatient area with possible or } \\
\text { confimmed case(s) (not within } 2 \text { metres) }\end{array}$ & $x$ & $x$ & $x$ & $x$ & $\gamma_{\text {sessional usee }}$ & $x$ & 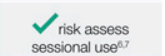 \\
\hline & 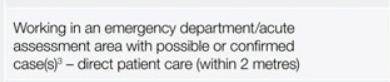 & $\checkmark$ single uses & $\checkmark$ single uses & $x$ & $x$ & $\checkmark$ sessional use $^{\circ}$ & $x$ & $\checkmark$ sessional use \\
\hline & 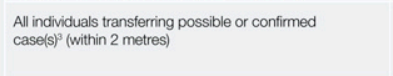 & $\checkmark$ single uses & $\checkmark$ single uses & $x$ & $x$ & 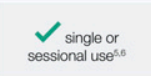 & $x$ & 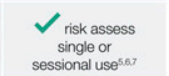 \\
\hline & 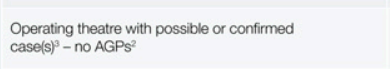 & $\checkmark$ singlo uses & $\checkmark$ single uses & 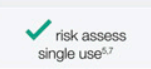 & $x$ & 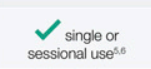 & $x$ & 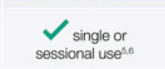 \\
\hline & 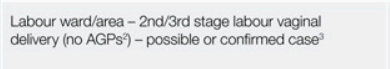 & $\checkmark$ single uses & $\checkmark$ single uses & $\checkmark_{\text {single use }}$ & $x$ & $\begin{array}{l}\text { sesingle or } \\
\text { sessional usee }\end{array}$ & $x$ & 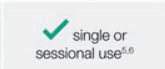 \\
\hline & 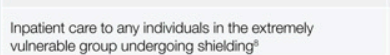 & $\checkmark$ single uses & $\checkmark$ single uses & $x$ & $\checkmark$ single uses & $x$ & $x$ & $x$ \\
\hline
\end{tabular}

FIGURE 3. Recommended PPE for healthcare workers by secondary care inpatient clinical setting, NHS and independent sector. Footnotes: ${ }^{1}$ This may be single or reusable face/eye protection/full face visor or goggles. ${ }^{2}$ List of aerosol-generating procedures (AGPs) is included in section 8.1 at www.gov.uk/government/publications/wuhan-novel-coronavirus-infection-prevention-andcontrol/covid-19-personal-protective-equipment-ppe. (Note: AGPs are undergoing further review at present). ${ }^{3} \mathrm{Case}$ is any individual meeting case definition for possible or confirmed case: https://www.gov.uk/government/publications/wuhan-novelcoronavirus-initial-investigation-of-possible-cases/investigation-and-initial-clinical-management-of-possible-cases-of-wuhannovel-coronavirus-wn-cov-infection. ${ }^{4}$ Higher-risk acute areas include intensive care units/high-dependency units; emergency department resuscitation areas; wards with noninvasive ventilation; operating theatres; endoscopy units (for upper respiratory; ear, nose, and throat; or upper gastrointestinal endoscopy); and other clinical areas where AGPs are regularly performed. ${ }^{5}$ Single use refers to disposal of PPE or decontamination of reusable items (e.g., eye protection or respirator) after each patient or after completion of procedure, task, or session; dispose or decontaminate reusable items after each patient contact as per standard infection control precautions. 6 Session refers to period during which health-care worker is undertaking duties in specific care setting/exposure environment (e.g., on ward round; providing ongoing care for inpatients). A session ends when health-care worker leaves care setting/exposure environment. Sessional use should always be risk-assessed and considered when there are high rates of hospital cases. PPE should be disposed of after each session or earlier if damaged, soiled, or uncomfortable. ${ }^{7}$ Riskassessed use refers to using PPE when there is anticipated or likely risk of contamination with splashes, droplets of blood, or body fluids. ${ }^{8}$ For explanation of shielding and definition of extremely vulnerable groups, see guidance at https://www.gov.uk/ government/publications/guidance-on-shielding-and-protecting-extremely-vulnerable-persons-from-covid-19/guidance-onshielding-and-protecting-extremely-vulnerable-persons-from-covid-19. ${ }^{9} \mathrm{Ambulance}$ staff conveying patients are not required to change or upgrade PPE for purposes of patient handover. Patient use of PPE: in cohort wards, communal waiting areas and during transportation, it is recommended that patients with suspected or confirmed cases wear surgical face mask if this can be tolerated. Aim is to minimize dispersal of respiratory secretions and to reduce both direct transmission risk and environmental contamination. Surgical face mask should not be worn by patients if there is potential for their clinical care to be compromised (e.g., when receiving oxygen therapy). (Reprinted from (19).)

to signify 2-m distancing and where guests of the facility should stand, including in elevators.

Waiting areas may need to be rearranged to facilitate social distancing, including chair removal to ensure 2-m distancing, but should be adaptable for accompanying persons when necessary. Special layouts may need to be considered for individuals in extenuating circumstances, such as prisoners being accompanied by wardens. If other waiting areas are available, once the risk is assessed they can be used for patients before and after injection.
If paper systems are still in use, pens should be cleaned for each patient. Any paperwork that the staff do not need to handle should be shown to the staff through the clear acrylic shield, when possible. Waiting areas should be cleaned with increased frequency to reduce cross contamination in accordance with the policies of the local facility or housekeeping staff. The clinical staff should endeavor to attend to patients as quickly as possible to minimize their time in the waiting area. Some facilities have enforced restrictions on entrance times before appointments to reduce patient interaction. 


\begin{tabular}{|c|c|c|c|c|c|c|c|c|}
\hline $\begin{array}{l}\begin{array}{l}\text { Aca } \\
\text { Public Health } \\
\text { England }\end{array} \\
\text { Recolle } \\
\text { and Social }\end{array}$ & 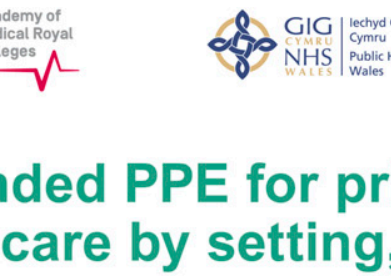 & $\begin{array}{l}\text { mary } \\
\text { NHS }\end{array}$ & $\begin{array}{l}\because \because \text { Hea } \\
\because \because \text { Sco } \\
\text { outro }\end{array}$ & $\begin{array}{l}\text { atien } \\
\text { ndep }\end{array}$ & $\begin{array}{l}\text { con } \\
\text { nder }\end{array}$ & $\begin{array}{l}\text { HSC) Public Health } \\
\text { Agency }\end{array}$ & ty & 11 \\
\hline Setting & Context & $\begin{array}{l}\text { Disposable } \\
\text { Gloves }\end{array}$ & $\begin{array}{l}\text { Disposable } \\
\text { Plastic Apron }\end{array}$ & $\begin{array}{l}\text { Disposable } \\
\text { fluid-repallent } \\
\text { coverall/gown }\end{array}$ & $\begin{array}{c}\text { Surgical } \\
\text { mask }\end{array}$ & $\begin{array}{l}\text { Fuid-resistant } \\
\text { (Ipes llR) } \\
\text { surgical mask }\end{array}$ & $\begin{array}{c}\text { Filtering face } \\
\text { piece respirator }\end{array}$ & $\begin{array}{l}\text { Eye/face } \\
\text { protection' }\end{array}$ \\
\hline Any setting & $\begin{array}{l}\text { Performing an aerosol generating procedure on } \\
\text { a possible or confirmed case }\end{array}$ & $\checkmark$ single use $e^{4}$ & $x$ & $\checkmark$ single use $e^{4}$ & $x$ & $x$ & $\checkmark$ single use ${ }^{a}$ & $\checkmark$ single use ${ }^{4}$ \\
\hline \multirow{2}{*}{ 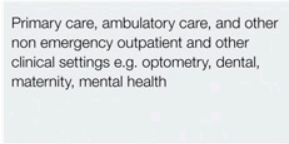 } & $\begin{array}{l}\text { Direct patient care - possible or confirmed case(s) } \\
\text { (within } 2 \text { metres) }\end{array}$ & $\checkmark$ single use $e^{4}$ & $\checkmark_{\text {single use }}$ & $x$ & $x$ & $\begin{array}{l}\sqrt{\text { single or }^{2}} \\
\text { sessional use }{ }^{45}\end{array}$ & $x$ & $\begin{array}{l}V_{\text {single or }} \\
\text { sessional use. }\end{array}$ \\
\hline & $\begin{array}{l}\text { Working in reception/communal area with possible } \\
\text { or confirmed casel(s) and unable to maintain } 2 \text { metres } \\
\text { social distances }\end{array}$ & $x$ & $x$ & $x$ & $x$ & $\checkmark_{\text {sessional use }}{ }^{s}$ & $x$ & $\mathrm{x}$ \\
\hline \multirow[t]{3}{*}{$\begin{array}{l}\text { Individuals own home } \\
\text { (current place of residence) }\end{array}$} & $\begin{array}{l}\text { Direct care to any member of the household where } \\
\text { any member of the household is a possible or } \\
\text { confirmed caser }\end{array}$ & $\checkmark$ single use & $\checkmark$ single use" & $x$ & $x$ & $\begin{array}{l}\sqrt{\text { single or }^{-1}} \\
\text { sessional use }\end{array}$ & $x$ & $\begin{array}{l}\checkmark \text { risk assess } \\
\text { single or } \\
\text { sessional use }\end{array}$ \\
\hline & $\begin{array}{l}\text { Direct care or visit to ary individuals in the extremely } \\
\text { vulnerable group or where a member of the } \\
\text { housenold is within the extremely vulnerable group } \\
\text { undergoing shielding" }\end{array}$ & $\checkmark$ single use ${ }^{4}$ & $\checkmark$ single use“ & $x$ & $\checkmark$ single use" & $x$ & $x$ & $\mathrm{x}$ \\
\hline & $\begin{array}{l}\text { Home birth where any member of the household } \\
\text { is a possible or confirmed case }{ }^{37}\end{array}$ & $\checkmark$ single use & $\checkmark$ single use $^{4}$ & $\checkmark$ single uset & $x$ & $\begin{array}{l}\checkmark \text { single or } \\
\text { sessional usets }\end{array}$ & $x$ & $\begin{array}{l}\checkmark_{\text {single or }} \\
\text { sessional use.5 }\end{array}$ \\
\hline $\begin{array}{l}\text { Community and social care, care home, } \\
\text { mental hitaeath inpatients and other } \\
\text { overnight care facilies e.g. learning } \\
\text { disability, hospices, prison heatlincare }\end{array}$ & $\begin{array}{l}\text { Facility with possible or confirmed case(s) - and direct } \\
\text { resident care (within } 2 \text { metres) }\end{array}$ & $\checkmark$ single use ${ }^{4}$ & $\checkmark$ single use" & $x$ & $x$ & $\checkmark$ sessional uses $^{s}$ & $x$ & $\begin{array}{l}\text { risk assess } \\
\text { sessional use }{ }^{5, n}\end{array}$ \\
\hline Any setting & Collection of nasopharyngeal swab(s) & $\checkmark_{\text {single use }}$ & $\begin{array}{l}\checkmark \text { single or } \\
\text { sessional use }\end{array}$ & $x$ & $x$ & $\begin{array}{l}\sqrt{\text { single or }} \\
\text { sessional use }\end{array}$ & $x$ & $\begin{array}{l}\checkmark \text { single or } \\
\text { sessional use. }\end{array}$ \\
\hline
\end{tabular}

FIGURE 4. Recommended PPE for primary, outpatient, community, and social care by setting, NHS, and independent sector. Footnotes: ${ }^{1}$ This may be single or reusable face/eye protection/full face visor, or goggles. ${ }^{2}$ List of aerosol-generating procedures is included in section 8.1 at www.gov.uk/government/publications/wuhan-novel-coronavirus-infection-prevention-and-control/covid19-personal-protective-equipment-ppe. (Note: aerosol-generating procedures are undergoing further review at present). ${ }^{3} \mathrm{Case}$ is any individual meeting case definition for possible or confirmed case: https://www.gov.uk/government/publications/wuhannovel-coronavirus-initial-investigation-of-possible-cases/investigation-and-initial-clinical-management-of-possible-casesof-wuhan-novel-coronavirus-wn-cov-infection. ${ }^{4}$ Single use refers to disposal of PPE or decontamination of reusable items (e.g., eye protection or respirator) after each patient or after completion of procedure, task, or session; dispose or decontaminate reusable items after each patient contact as per standard infection control precautions. ${ }^{5}$ Single session refers to period when health-care worker is undertaking duties in specific care setting/exposure environment (e.g., on ward round) providing ongoing care for inpatients. Session ends when health-care worker leaves care setting/exposure environment. Sessional use should always be risk-assessed and considered when there are high rates of hospital cases. PPE should be disposed of after each session or earlier if damaged, soiled, or uncomfortable. ${ }^{6}$ Nonclinical staff should maintain 2-m social distancing, through marking out controlled distance; sessional use should always be risk-assessed and considered when there are high rates of community cases. ${ }^{7}$ Initial risk assessment should take place by phone before entering premises or at 2-m social distance on entering; when health or social care worker assesses that individual is symptomatic with suspected/confirmed cases, appropriate PPE should be put on before providing care. ${ }^{8}$ Risk-assessed use refers to using PPE when there is anticipated/likely risk of contamination with splashes, droplets or blood, or body fluids. ${ }^{9}$ For explanation of shielding and definition of extremely vulnerable groups, see guidance at https://www.gov.uk/government/publications/guidance-on-shielding-and-protecting-extremelyvulnerable-persons-from-covid-19/guidance-on-shielding-and-protecting-extremely-vulnerable-persons-from-covid-19. (Reprinted from (19).)

\section{Staffing}

Staffing levels may return to normal but with the possibility of extended hours to incorporate the backlog of patients. All staff should be educated on updated infection control measures. Time, distance, and shielding - concepts the technologists should be quite familiar with - will come in handy during a pandemic and its recovery phase, as similar rules apply. When possible, staff should work $2 \mathrm{~m}$ apart and wear a mask at all times. Staff should also decontaminate their hands whenever entering and leaving a room and before and after handling food, in addition to before and after patient contact. Staff in vulnerable groups may need further adjustments, which should be discussed with management on a case-by-case basis.

The effects of the pandemic on staff mental health should also be considered. Experiences are varied, with some staff having been furloughed, some having volunteered in field hospitals or in alternate areas of the hospital, and some continuing to work at their normal workplace. The stress of being in a pandemic, alongside the stress of caring for patients, can take its toll. Therefore, health and wellness teams should be made accessible for any staff that needs them. 
Staff should be trained to look for signs of COVID-19 on imaging when possible. Clear protocols for positive findings should be outlined and adhered to, with real-time radiologist support in indeterminate cases.

Some facilities have started testing patient-facing staff for COVID-19 on a regular basis. This testing will help to identify infected persons, potentially before symptoms arise. Some sites are also able to offer antibody testing.

\section{Attending to Patients}

It is best to have a plan with colleagues on how to attend to patients. It is important to minimize exposure to multiple colleagues by having only one person deal with the patient when possible. If the facility normally asks patients to change into a gown, it may be a good idea to rethink that policy to minimize their exposure to lockers and other communal areas. If changing is a must, gowns and linens should not be placed in a changing room before patients enter but instead should be handed to patients as they enter to minimize cross contamination with others. Lockers, chairs, and benches in changing rooms must be cleaned after each patient departs. Handling of the patient's belongings by anyone other than the patient should be minimized, when possible. The attending staff should be wearing PPE in accordance with local policy and ensure that they wash their hands at all necessary intervals. Technologists should have all supplies ready to cannulate the patient, with extra available, so that they are not compromising stores or leaving the room to obtain additional items. When taking the patient's history, staff should adhere to social distancing, when possible. Some patients may be hearing-impaired and have trouble understanding anyone wearing a mask (because the voice is muffled and lip reading is not possible). Instructions should be spoken slowly and clearly for all patients to ensure that they understand and consent to the procedure.

When it is time to leave the room for any reason, proper doffing procedures must be followed. It may be necessary to perform mock scenarios to ensure policies are appropriate and understood by all staff.

\section{Emergency Response Planning}

COVID-19 kits have become part of emergency carts and are checked on a daily basis. These kits include a higher level of PPE to be used by those attending the emergency (Figs. 3 and 4) and may differ depending on the facility. Basic life support has also changed in the time of COVID-19. The Resuscitation Council UK has updated its guidance to incorporate risk reduction techniques related to the pandemic. Highlights include assuming everyone has COVID-19 and beginning no cardiopulmonary resuscitation until the correct PPE is worn. This guidance is facilitated by the addition of a gatekeeper at the door of the emergency. This person should not let anyone enter the emergency area who has not donned the proper PPE (18). The assumption that every person has COVID-19 is excellent advice applicable to every situation regardless of whether it is an emergency.

\section{CONCLUSION}

A new normal for molecular imaging departments has been created. Molecular imaging technologists are adept at changing while still providing excellent care. Technologists have trained on new cameras and new software and are given new isotopes and protocols frequently. Although adjustments should be easily adopted by technologists, it is important to remember to comfort the patient throughout. They are the ones potentially vulnerable and scared. Technologists must reassure patients that they are doing everything possible to minimize any exposure to COVID-19. The patient's peace of mind is important and should be looked after.

The aforementioned steps have helped molecular imaging departments in the United Kingdom to remain open throughout the pandemic without compromising patient care. We appreciate that as the world changes, so will the guidance on how to deal with COVID-19, and that adaptations will continue to be made.

\section{DISCLOSURE}

No potential conflict of interest relevant to this article was reported.

\section{REFERENCES}

1. WHO (COVID-19) homepage: global-the United Kingdom. World Health Organization website. https://covid19.who.int/region/euro/country/gb. Retrieved June 20, 2020. Updated July 29, 2020. Accessed July 29, 2020.

2. COVID-19 dashboard by the Center for Systems Science and Engineering (CSSE) at Johns Hopkins University (JHU). Johns Hopkins University of Medicine website. https://coronavirus.jhu.edu/map.html. Retrieved June 20, 2020. Updated July 29, 2020. Accessed July 29, 2020.

3. Conn D, Lewis P. Documents contradict UK government stance on Covid-19 'herd immunity.' The Guardian website. https://www.theguardian.com/world/ 2020/apr/12/documents-contradict-uk-government-stance-on-covid-19-herd-immunity. Published April 12, 2020. Accessed July 29, 2020.

4. Easton M. Coronavirus: care home residents could be 'cocooned.' BBC website. https://www.bbc.co.uk/news/uk-51828000. Published March 11, 2020. Accessed July 29, 2020.

5. D'Souza G, Dowdy D. What is herd immunity and how can we achieve it with COVID-19? Johns Hopkins Bloomberg School of Public Health website. https:// www.jhsph.edu/covid-19/articles/achieving-herd-immunity-with-covid19.html. Published April 10, 2020. Accessed July 29, 2020.

6. What you can and can't do during the coronavirus UK lockdown. ITV website. https://www.itv.com/news/2020-03-23/what-you-can-and-can-t-do-in-the-threeweek-coronavirus-uk-lockdown/. Published March 23, 2020. Accessed July 29, 2020.

7. Coronavirus: Nightingale Hospital opens at London's ExCel Centre. BBC website. https://www.bbc.co.uk/news/uk-52150598. Published April 3, 2020. Accessed July $29,2020$.

8. Illman J. NHS block books almost all private hospital sector capacity to fight covid-19. HSJ website. https://www.hsj.co.uk/policy-and-regulation/nhs-blockbooks-almost-all-private-hospital-sector-capacity-to-fight-covid-19/7027196.article. Published March 21, 2020. Accessed July 29, 2020.

9. Coronavirus: face coverings compulsory on public transport in England. BBC website. https://www.bbc.co.uk/news/uk-53045386. Published June 15, 2020. Accessed July 29, 2020.

10. Buscombe JR, Notghi A, Croasdale J, et al. COVID-19: guidance for infection prevention and control in nuclear medicine. Nucl Med Commun. 2020;41:499-504.

11. Gnanasegaran G, Huang HL, Williams J, Bomanji J. Coronavirus pandemic: what nuclear medicine departments should know. J Nucl Med Technol. 2020;48:89-97. 
12. ARSAC application forms. Gov.UK website. https://www.gov.uk/government/ publications/arsac-application-forms. Published April 17, 2020. Updated April 20, 2020. Accessed July 29, 2020.

13. Iball G. DRLs for hybrid imaging. Presented at: UK Imaging and Oncology Online 2020; June 9, 2020.

14. Stevens BJ, Wade D. Improving continuing professional development opportunities for radiographers: a single centre evaluation Radiography (Lond). 2017;23: 112-116.

15. BSNMS guidance for Covid-19 recovery phases. British Nuclear Medicine Society website. https://cdn.ymaws.com/www.bnms.org.uk/resource/resmgr/news_\&_ press_office/news/covid-19_recovery_phase_guid.pdf. Accessed July 29, 2020.

16. HCA Healthcare UK: your safety comes first. YouTube website. https://www. youtube.com/watch?v=awiVDGURODY. Published June 25, 2020. Accessed July 29,2020 .
17. Our world has changed, we have too. HCA Healthcare UK website. https:// www.hcahealthcare.co.uk/your-safety-comes-first. Accessed July 29, 2020.

18. Statements and resources on COVID-19 (coronavirus), CPR and resuscitation. Resuscitation Council UK website. https://www.resus.org.uk/covid-19-resources. Accessed July 29, 2020.

19. COVID-19: infection prevention and control (IPC). Gov.UK website. https:// www.gov.uk/government/publications/wuhan-novel-coronavirus-infection-preventionand-control. Published January 10, 2020. Updated July 23, 2020. Accessed July 29, 2020.

20. Song Y, Lan X. Key protection management of nuclear medicine imaging during the outbreak of COVID-19. American College of Nuclear Medicine website via Amazon Web Services website. https://s3.amazonaws.com/rdcms-snmmi/files/ production/public/ACNM/ACNM\%20COVID19\%20-\%20Wuhan\%20NucMed\% 20Experience.pdf. Accessed July 29, 2020. 